\title{
Temporal and Spatial Characteristics of Typhoon Extreme Rainfall in Taiwan
}

\author{
Shih-Hao SU \\ Taiwan Typhoon and Flood Research Institute, Taipei, Taiwan \\ Hung-Chi KUO, Li-Huan HSU and Yi-Ting YANG \\ Department of Atmospheric Sciences, National Taiwan University, Taipei, Taiwan \\ (Manuscript received 2 October 2011, in final form 2 April 2012)
}

\begin{abstract}
We studied the temporal and spatial characteristics of extreme typhoon rainfall in Taiwan using Central Weather Bureau hourly precipitation data from 21 surface stations during the past 51 years (1960-2010). Extreme rainfall is defined as 95th percentile intensity of total rain events, or equivalently, rain events greater than $9 \mathrm{~mm} \mathrm{hr}^{-1}$ which contribute $40 \%$ to the total rain amount in Taiwan. It was found that approximately $70 \%(20 \%)$ of extreme rain is in the typhoon season (Mei-Yu) from July to October (from May to June). There are significant variations of typhoon extreme rainfall over the annual and decadal time scales, with larger extreme rainfall values and events in the periods of 1960-1976 and 1994-2010, and less in the 1977-1993 period. The recent 1994-2009 period has the most extreme rainfall and events, as well as, inter-annual variability. In contrast, there are strong inter-annual variations of Mei-Yu extreme rainfall, but no significant decadal variations. The averaged typhoon rain intensity, however, is about the same, being $19 \mathrm{~mm} \mathrm{hr}^{-1}$ in all these three periods. Our analysis indicates that the typhoon extreme rainfall spatial pattern is phased locked with the Central Mountain Range, Taiwan. In general, the amount of extreme rainfall was related to the typhoon translation speed and duration time, but not typhoon intensity. Slower speeds and longer duration time lead to larger extreme rainfall values. Our analysis also indicate that the mean duration time of Taiwan landfall typhoons with northern tracks (tracks north of 23 degrees latitude) is about 3 hours longer than that of southern track typhoons in the last 51 years, and is more likely to produce three times as much extreme rainfall. The interactions of summer or winter monsoons with typhoons are also important factors that may contribute to the extreme rainfall in Taiwan. Examples of extreme rainfall due to typhoon circulation interaction with summer and winter monsoon flows are presented. Monsoon water vapor supply, typhoon slow translation speed, and mesoscale convection due to typhoon-monsoon flow interactions are the key factors in extreme precipitation events.
\end{abstract}

\section{Introduction}

Taiwan is located in the East-Asian monsoon region with annual precipitation of $2,500 \mathrm{~mm}$. The destructive power of typhoons in Taiwan is related to the Central Mountain Range (CMR, see Fig. 1), a complex terrain consisting of steep mountains exceeding $3000 \mathrm{~m}$.

Corresponding author and present affiliation: Hung-Chi

Kuo : Department of Atmospheric Sciences, National

Taiwan University, Taipei, Taiwan (R.O.C.)

E-mail: kuo@as.ntu.edu.tw

C2012, Meteorological Society of Japan
With global warming in mind, the changes in precipitation due to climate change are of major concern. Hsu and Chen (2002) and Lu and May (2003), used 5 stations over the Taiwan plains with daily rainfall data from 1920 to 1995 to suggest that total rainfall in Taiwan had no clear trend in the past 76 years. Lu et al. (2007), using the hourly rainfall data, further analyzed the long-term variations of extreme rainfall (ER) frequency (define as the top $10 \%$ intensity in each station) during 1951-2005. Their results indicate a significant increasing trend in ER frequency in Taipei (northern Taiwan) and Hualien (east coast of Taiwan) 


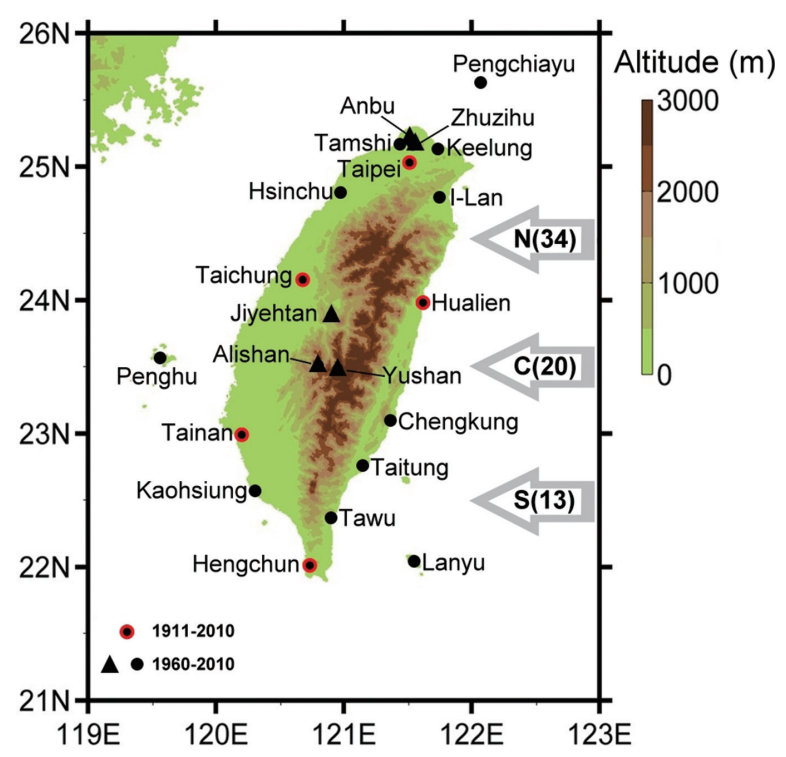

Fig. 1. Manual observation stations of central weather bureau (CWB) in Taiwan. There are 21 CWB stations, with 5 mountain stations indicated by triangle symbols. The 5 red circle stations have a 100-year data length. The typhoon case numbers for type 2 (North, $24^{\circ} \mathrm{N}-25^{\circ} \mathrm{N}$ ), type 3 (Center, $23^{\circ} \mathrm{N}-24^{\circ} \mathrm{N}$ ) and type 4 (South, $22^{\circ} \mathrm{N}-23^{\circ} \mathrm{N}$ ) tracks are indicated.

stations. Three other stations (Taichung, Tainan and Hengchun, Fig. 1) over the west coast plain area did not have a significant trend after 1979. On the other hand, Hsu and Chen (2002) and Hung and Kao (2010) indicated that the total rain frequency, especially for the light rain component, has decreased in recent years. Liu et al. (2009) analyzed Taiwan daily rain intensity data for 17 stations from 1961-2005 and found significant inter-annual differences, along with an increasing of top $10 \%$ rain intensity events and decreasing of bottom $10 \%$ events. The decrease of the light rain frequency may be due to the global warming lapse rate change to a more stable atmosphere (Hartmann et al. 2000). Hung et al. (2004) indicated that Taiwan spring rainfall has a significant decadal variation signal, which is related to the 20-30 year cycle of the Pacific Decadal Oscillation (PDO), since the early 20th century. Their study used surface rainfall data from four surface stations in northern Taiwan and global monthly sea surface temperature to analyze the relationship with the rainfall variation and PDO index. Their results indicate that the positive phase of the PDO enhances southwesterly flow near the east coast of Taiwan and causes stronger spring rainfall. The negative phase of the PDO is characterized by stronger north-easterly flow near Taiwan which can cut off the water vapor supply and decrease spring rainfall. The decadal variation of the spring rain, however, is in an order of magnitude smaller than that of the inter-annual variation.

Fujibe et al. (2006) used surface data from 51 stations data in Japan to analyze the daily rainfall intensity and frequency variations from 1901-2004. They indicated that the top $10 \%$ ER events were increasing $2.3 \%$ every 10 years, and this trend was more significant over western Japan in the fall season. To monitor climate change, hourly rainfall data from 1,000 regional meteorological observation stations from 1979-2009 were analyzed by the Japan Meteorological Agency (JMA) (2010). This analysis shows that the frequency of over $50 \mathrm{~mm} \mathrm{hr}^{-1}$ ER events has shown a statistically significant increasing tendency, but not for $80 \mathrm{~mm} \mathrm{hr}^{-1}$ rainfall events. In the United States, precipitation has increased an average of about $7 \%$ over the past 100 years (Karl et al. 2009). The amount of ER ( $99 \%$ intensity) has increased approximately $20 \%$ on average in the past century, with more significant increases in the Northeast and Midwest of United States. According to their statistical analyses, the extreme daily rainfall events from 1958-2007 increased about $67 \%$ in the Northeastern U.S. and 31\% in the Midwest. General precipitation increasing trends have been reported in different climate zones (Karl and Knight 1998; Ho et al. 2004; Fujibe et al. 2005; Goswami et al. 2006; Lau and Wu 2007; Piao et al. 2010).

Previous rainfall studies over Taiwan, such as Lu and May (2003), Liu et al. (2009) and others, have not used hourly rainfall data and all surface stations in their analysis. There are 3-hour rainfall data available for 5 surface stations before 1960 . These 5 stations are over the plains area, and thus may not effectively represent the ER in the mountainous regions. Moreover, previous analyses did not distinguish the weather systems, such as typhoons and Mei-Yu fronts on ER. Using daily rain rate data may cause the underestimation of extreme events in the short-term weather phenomena such as typhoon and Mei-Yu rainfall. In this paper, we study the temporal and spatial characteristics of typhoon ER (95th percentile) in Taiwan using hourly rainfall data with 21 Central Weather Bureau (CWB) surface stations from 1960-2010. This data set is the most complete rainfall data available in the recent 51 year period in Taiwan. Section 2 describes the data and analysis method. Section 3 discusses the temporal and spatial characteristics of typhoon ER in Taiwan. Additional characteristics of Taiwan typhoon 
(a)

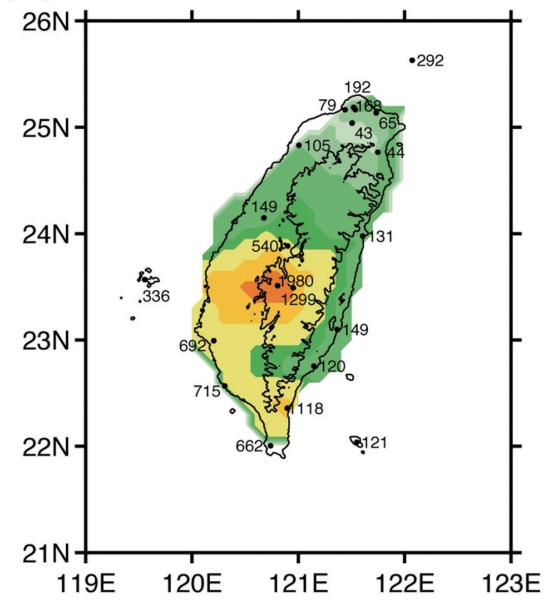

(b)

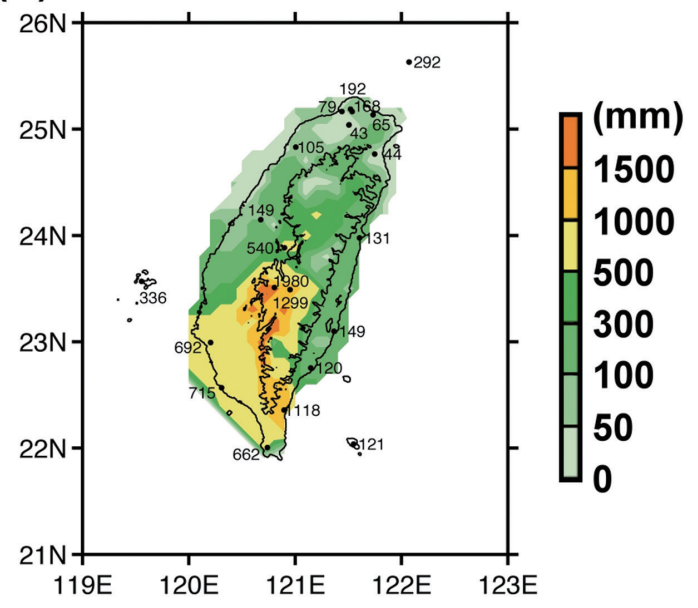

Fig. 2. Spatial distributions of typhoon accumulated rainfall for Typhoon Morakot (2009) with (a) 21 CWB surface stations and (b) 429 available rain gauge stations.

ER are addressed in Section 4. Section 5 is a summary.

\section{Data and method}

We use CWB hourly precipitation data for the 51-period (1960-2010) from 21 surface stations (Fig. 1). The 5 mountain stations, which are located at elevations higher than $600 \mathrm{~m}$ altitude, are indicated by triangle symbols. Note that there are no mountain surface stations over the slopes of CMR south (north) of the Alishan (Jiyehtan) station. The lack of mountain stations may underestimate the rainfall amount in both the northern and southern CMR slopes. The numbers of westward typhoon with track type 2(N), type 3(C) and type 4(S) are shown in Fig. 1. The track types are classified by the CWB according to typhoon position at 122 degree longitude, and the latitude range for track types $2(\mathrm{~N}), 3(\mathrm{C})$, and $4(\mathrm{~S})$ are 22-23, 23-24, and 24-25 degrees, respectively. To examine ER in Taiwan, we analyzed all of CWB hourly precipitation data for 21 stations from 1960 to 2010 . Figure 2 is the rainfall distribution of $21 \mathrm{CWB}$ stations and all available 449 rain gauge stations for Typhoon Morakot (2009). Figure 2 shows that the rainfall distribution from the 21 stations is in general agreement with detailed rain gauge observations. The rainfall in Fig. 2a, as expected, is underestimated over the CMR southern slopes.

Data from the $21 \mathrm{CWB}$ stations account for about $9.4 \times 10^{6}$ events. The percentage sorting method, which has been widely used in extreme weather event identification (Kunkel et al. 1999; Manton et al. 2001; Zhai et al. 2005), is applied here to determine the ER events. The zero rainfall events are excluded in this sorting, and the rain rate of all non-zero rain events were greater than or equal to $0.1 \mathrm{~mm} / \mathrm{hr}$. The total "non-zero rain events" were about $1.2 \times 10^{6}$ hours which is about $13 \%$ of total available data. The zero rainfall events also show an increasing trend in recent years, especially during the Mei-Yu season. However, there is very large annual variability. The percentile choice of ER may seem to be arbitrary as different thresholds have been used in earlier studies. The choice of the criteria is often a balance of "extremeness" vs. the number of samples needed to be statistically significant. The 90th and 95th percentile and the 95th and 99th percentile criteria appear to be popular choices in previous studies for defining ER events (e.g., Peralta-Hernández et al. 2009; Tolika et al. 2007; Haylock et al. 2006; Salinger and Griffths 2001; Haylock and Nicholls 2000; Suppiah and Hennessy 1998). Figure 3 gives the inter-annual variations of ER, the amount, the frequency and the intensity for criteria of 90th, 95th, 99th, and 99.9th percentile. The 90th and 95th percentile ER amount and frequency yield a similar pattern, with large inter-annual variations and an increasing trend in the last fifteen years. The 99th and 99.9th percentile ER also increased in the last fifteen years, but the frequency trend of increase is not that significant. The mean rain intensity as defined by dividing the rainfall amount to the event hours, however, shows no significant annual variation for the 90th, 95th and 99th percentile ER intensity. Table 1 gives the average extreme rainfall amount of all events, 90th, 95th, 99th, 

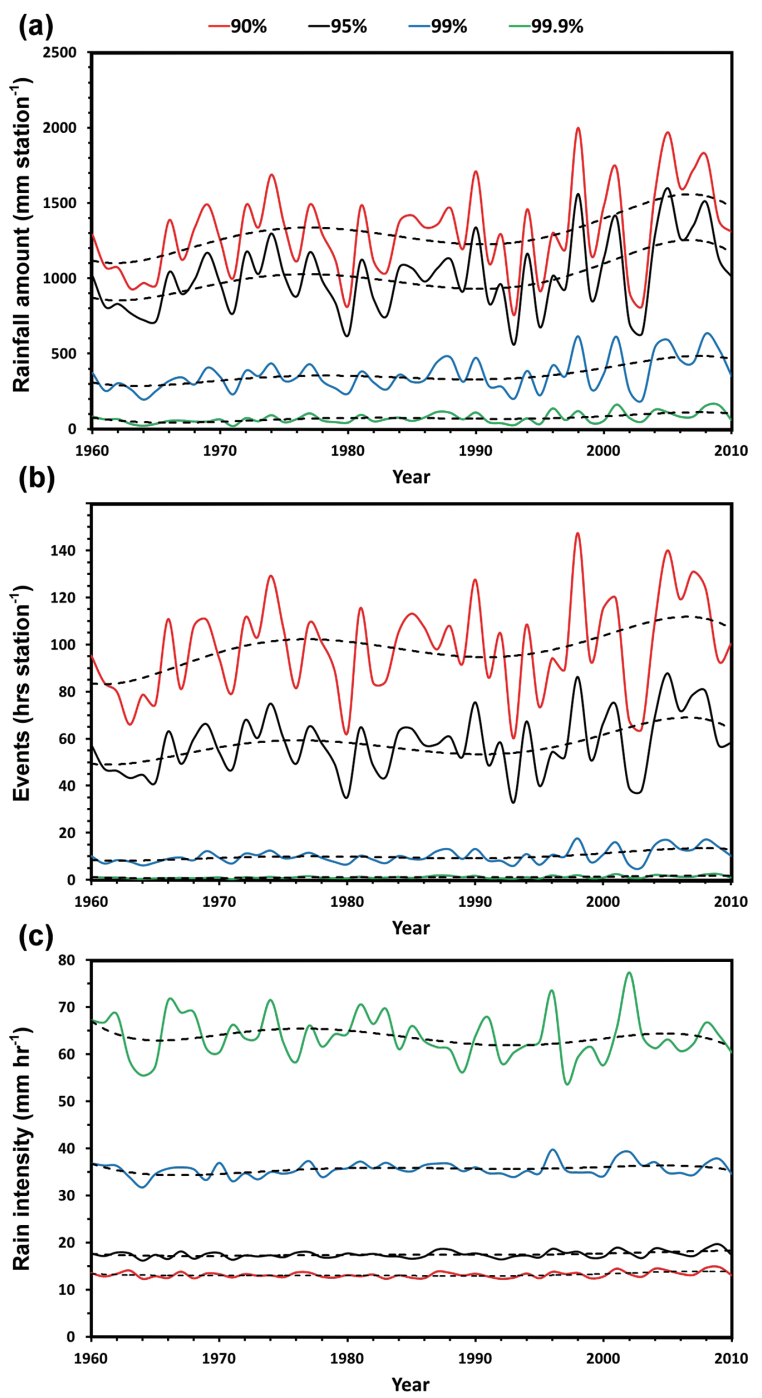

Fig. 3. The annual variations of extreme rainfall (a) amount, (b) frequency, and (c) averaged rain intensity from 1960-2010. The different criteria of rainfall percentiles (90th, 95th, 99th, and 99.9th) are indicated by different colors; the 6th order regressions are shown by dashed lines.

99.5th, and 99.9th percentiles, and the correlation between yearly values of all event rainfall amounts and ER values. The 95th percentile ER contributes approximately $40 \%$ to the total rainfall amount in Taiwan and correlates well (approximately 0.9 correlation) with the yearly total rainfall amount the total number of ER events was about $6.9 \times 10^{4}$ hours for $21 \mathrm{CWB}$ stations. Thus we use the 95 th percentile intensity rain events (rain intensity greater than $9 \mathrm{~mm} \mathrm{hr}^{-1}$ in our data) as the bench mark for the ER study.

Typhoons and Mei-Yu front systems are the two most prominent major weather systems which cause ER in Taiwan. We define typhoon rainfall as the rainfall due to all the 351 typhoons affecting Taiwan (typhoon centers are within 2 degrees from Taiwan coast) in 1960-2010 period plus the rainfall in the major typhoon season from July to October. Due to the interaction of typhoons and the monsoon circulation, significant rainfall may result from the enhanced summer monsoon flow in the typhoon post-landfall period. There may also be significant rainfall over northern Taiwan due to the enhanced winter monsoon flow when typhoons are near the Philippines. To simplify the discussion, we have included the rainfall in July to October months plus the typhoon events as one category typhoon season (TYS) rainfall. Since all the Mei-Yu systems occur in May and June, we define the Mei-Yu rainfall (MY) as the rainfall amount in these two months (typhoon rainfall excluded). Finally, the winter (WI) and spring (SP) rainfalls (excluding typhoon rainfall) are defined as the rainfall from November to January, and February to April, respectively.

Hourly typhoon center positions according to the CWB typhoon database (Wang 1980; Shieh et al. 1998) are used to calculate the typhoon translation speed. Radar and satellite analyses are widely applied to define the landfall/departure positions and times of typhoon from 1977 to 2010. The radar and satellite data provide greater accuracy in determining typhoon landfall/departure positions in Taiwan. With landfall/ departure positions and times, translation speed (linear distance divided by duration time) can be estimated. The maximum wind speed of a typhoon when the center was within $1^{\circ}$ latitude of Taiwan was used to define the intensity of the typhoon. All these data can be found in the CWB typhoon database.

Of all the typhoons affecting Taiwan, 96 typhoons actually made landfall in Taiwan in the 1960-2010 period, and of these, 84 made landfall along the east coast of Taiwan. The CWB classified 6 types of tracks with the type $2(\mathrm{~N})$, type $3(\mathrm{C})$, and type $4(\mathrm{~S})$ being most common (Fig. 1). There are 67 typhoons total in these tracks. We also examined the total rainfall $(\mathrm{mm})$ from all the CWB surface stations during typhoon pre-landfall (from $100 \mathrm{~km}$ offshore to typhoon landfall position), landfall, and post-landfall periods (defined as the time from the typhoon departure point to 100 km offshore). For the 1960-1976 period, post-landfall positioning was not reliable, so post-landfall rainfall calculations are only from 1977-2010, when radar and satellite data are available for this analysis. 
Table 1. The average extreme rainfall amount of all events, 90th, 95th, 99th, 99.5th, and 99. th $^{\text {th }}$ percentiles and the correlation between yearly values of all events rainfall and extreme rainfall values.

\begin{tabular}{ccccccc}
\hline & $\begin{array}{c}\text { All } \\
\text { Events }\end{array}$ & 90th & 95th & 99 th & 99.5 th & 99.9 th \\
\hline Criteria & $>0 \mathrm{~mm}$ & $\geq 6 \mathrm{~mm}$ & $\geq 9 \mathrm{~mm}$ & $\geq 24 \mathrm{~mm}$ & $\geq 30 \mathrm{~mm}$ & $\geq 50 \mathrm{~mm}$ \\
\hline $\begin{array}{c}\text { Average Rainfall } \\
\text { Amount } \\
\left(\text { mm ylr }^{-1}\right)\end{array}$ & 52594 & 27407 & 21248 & 7554 & 5244 & 1510 \\
\hline $\begin{array}{c}\text { Correlation with } \\
\text { All Events }\end{array}$ & $100 \%$ & $93 \%$ & $89 \%$ & $72 \%$ & $65 \%$ & $50 \%$ \\
\hline
\end{tabular}

\section{The temporal and spatial characteristics of typhoon extreme rainfall in Taiwan}

Figure 4 shows the annual variations in ER amount, frequency and average intensity from 1960-2010. The total ER amount in Taiwan is dominated by TYS (68\%) and MY (22\%), with the other $10 \%$ from the WI and SP. The total ER amount annual variation is strongly related to the TYS ER amount, with correlations of 0.89 for rainfall amount and 0.86 for frequency. The MY correlations for rain amount and frequency are 0.52 and 0.56 , respectively. Figure 4 indicates that both ER amount and frequency have saliently increased in the last fifteen years in Taiwan. This recent trend is primarily related to the change in ER in the typhoon season. Figure 4 also reveals that there is a strong annual variation of the MY ER amount, but with no recent trend increase. Finally, Fig. $4 \mathrm{c}$ shows that the average ER intensity of TYS has increased slightly at a rate of $0.02 \mathrm{~mm}$ per year in the past 51 years with the averaged rain intensity approximately $19 \mathrm{~mm} \mathrm{hr}^{-1}$.

Figure 5 shows the variations of monthly average temperature, relative humidity, and water vapor mixing ratio averaged over the $21 \mathrm{CWB}$ surface stations from 1960-2010. The three linear trends indicate that the average temperature is increasing, the relative humidity is decreasing, and the water vapor mixing ratio remains nearly constant. The increase of ER in the last fifteen years is not attributable to the increase of water vapor locally, which shows little if any change over this period. Therefore an increase in water vapor transport is required to account for the increase in the ER.

Figure 6 is the spatial distribution of ER amount for WI, SP, MY and TYS. The WI ER amount (Fig. 6a), is generally caused by surges in East-Asian winter monsoon, such that its maximum occurs on the windward side of the northeast part of Taiwan. The SP and
MY rainfall amount are often associated with frontal systems so that most of ER amount is found over western Taiwan (Figs. 6b, c). For the TYS, ER amount occurs on both the east and the west sides of the island. Since most typhoons make landfall on the east coast, Fig. 6d reveals that the east side of Taiwan has larger ER values than that of other seasons. Moreover, Fig. 6 indicates that there is a peak in ER for the SP, MY and TYS over the Alishan region in the southern CMR. This suggests that topographic forcing is very important in producing ER in these seasons. This kind of topographic phased locked precipitation pattern was also noticed in other studies of typhoons and Mei-Yu fronts (Chang 1982; Chen et al. 1991; Chang et al. 1993). Figure 7 is the same as Fig. 6 except for the frequencies (event hours per year). The spatial distribution in ER frequency is in general agreement with the distribution of rainfall with large values of ER often associated with higher frequency. Figure 8 shows the spatial distributions in the 95th percentile ER averaged rain intensity (the ER value divided by ER event hours) during 1960-2010 for WI, SP, MY and TYS. The peak rain intensity over the Alishan mountain station is about $21 \mathrm{~mm} \mathrm{hr}^{-1}$ for the TYS. The peak MY rain intensity, however, is $19 \mathrm{~mm} \mathrm{hr}^{-1}$ located north of the central Taiwan Hsinchu station. Rain intensities for most stations are between $14 \mathrm{~mm} \mathrm{hr}^{-1}$ and $20 \mathrm{~mm} \mathrm{hr}^{-1}$.

Liu and Chan (2008) showed the decadal variation of typhoon tracks over the Western North Pacific with more typhoons approaching the Taiwan area in the periods of 1960-1976 and 1994-2010 (as opposed to the case with less typhoons approaching the South China Sea area). We examined to see if such an inter-decadal variation of typhoon tracks affected the typhoon ER in Taiwan. Similar to Liu and Chan (2008), we divided the 51 years of data into three 17-year periods: 19601976, 1977-1993, and 1994-2010. Figure 9 shows 

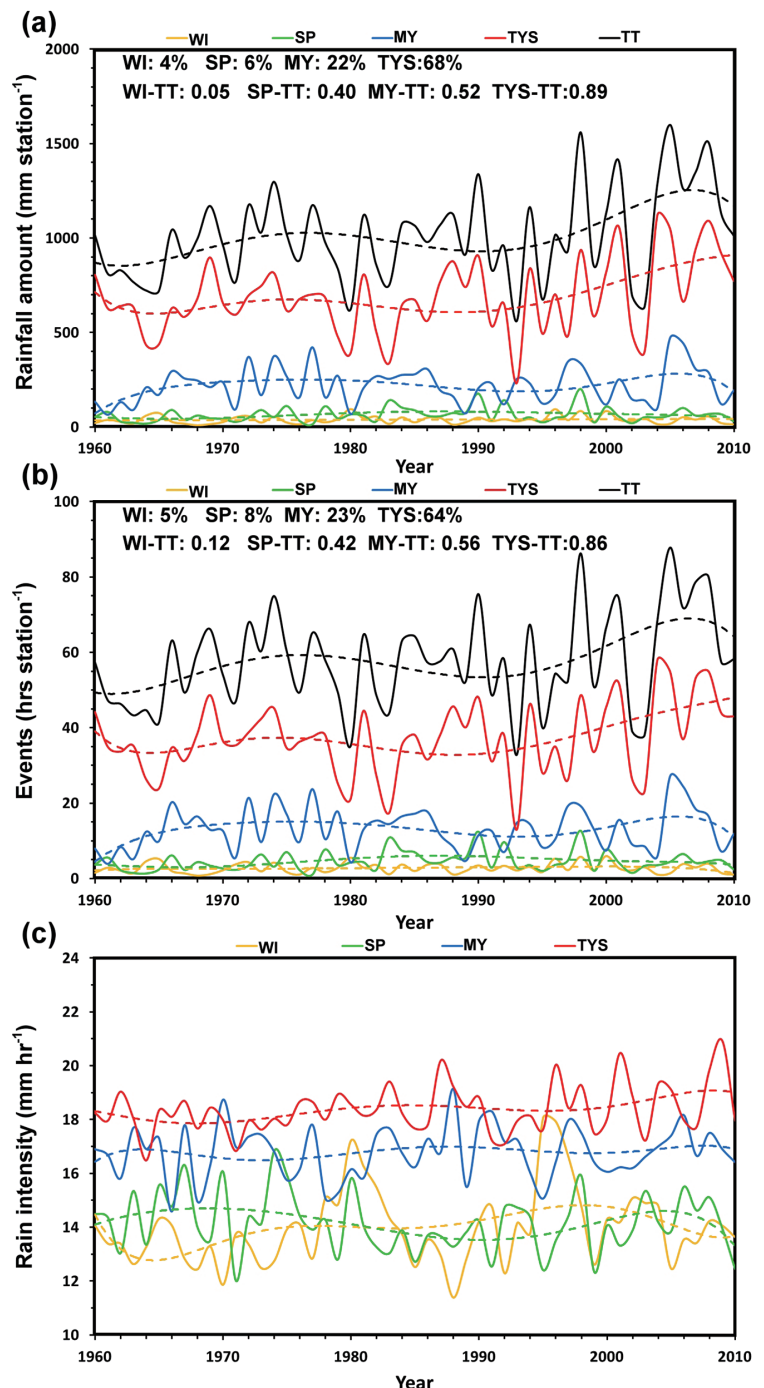

Fig. 4. The annual variations of 95th percentile extreme rainfall (a), frequency (b), and averaged rain intensity (c) from 1960-2010. Yellow, green, blue, red, and black solid lines represent winter, spring, Mei-Yu, typhoon season, and total amount. The 6th order regressions are indicated by dashed lines. The percentages and the correlation coefficients between different seasons and total extreme rainfall are shown on top of (a) and (b).

the spatial distribution of typhoon ER, frequency and intensity for each decadal period. The rainfall patterns are similar to those in Figs. 6d, 7d, 8d; with more rainfall over the east coast and a maximum of ER at Alishan mountain station. The variation in typhoon ER

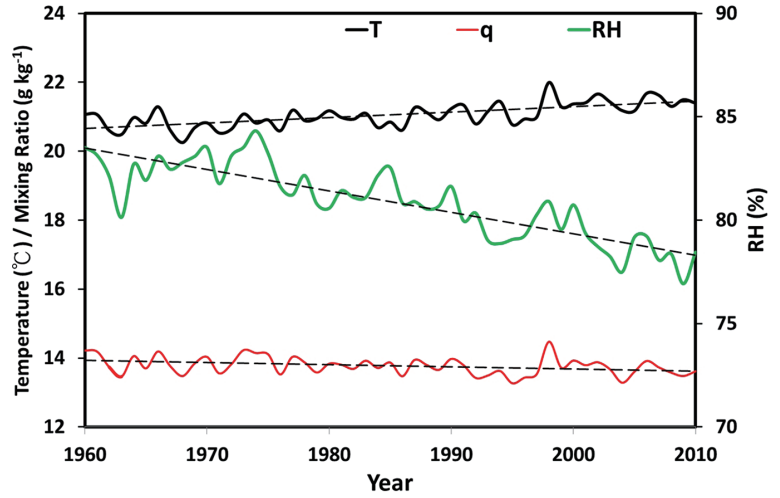

Fig. 5. The linear trend of monthly average surface temperature $(\mathrm{T})$, relative humidity $(\mathrm{RH})$ and water vapor mixing ratio (q) from 1960-2010. Dashed lines are the linear trends.

shows greater values and frequency in the periods of 1960-1976 and 1994-2010, with less in the 1977-1993 period. The averaged ER for each station is $387.5 \mathrm{~mm}$ $\mathrm{yr}^{-1}, 339.7 \mathrm{~mm} \mathrm{yr}^{-1}$ and $490.4 \mathrm{~mm} \mathrm{yr}^{-1}$ for the three decadal periods, respectively. The decrease in the averaged ER from the first period to the second period is 47 $\mathrm{mm} \mathrm{yr}^{-1}$, which is much smaller than the increase from the second period to the recent period $\left(150 \mathrm{~mm} \mathrm{yr}^{-1}\right)$. Figure 9 also indicates decadal rain intensity changes, with the largest rain intensity in the most recent decade.

Figure 10 shows the annual variation of typhoon numbers in the vicinity of Taiwan according to the CWB database, the annual total landfall duration time and the landfall duration time per typhoon in each year. Figure 10 suggests a significant increase in typhoon duration and typhoon numbers affecting Taiwan in the recent 1994-2010 period. The averaged total duration time is $38 \mathrm{hr} \mathrm{yr}^{-1}, 28 \mathrm{hr} \mathrm{yr}^{-1}$ and $40 \mathrm{hr} \mathrm{yr}^{-1}$ in the three decadal periods, respectively. The duration time per typhoon is about the same $16 \mathrm{hrs}$ for the first 2 decadal periods and $20 \mathrm{hrs}$ in the most recent decadal period. The decadal variations in typhoon duration and the typhoon numbers over Taiwan area may be, in part, due to changes in the decadal tropical cyclone (TC) track over the Western North Pacific (Liu and Chan 2008). However, the cause for the longer duration time per typhoon in the recent decadal period remains to be studied.

\section{Central mountain range impact on the typhoon extreme rainfall}

To investigate the impact of the CMR on typhoon ER, we examine the type $2(\mathrm{~N}), 3(\mathrm{C})$, and $4(\mathrm{~S})$ tracks 
(a)

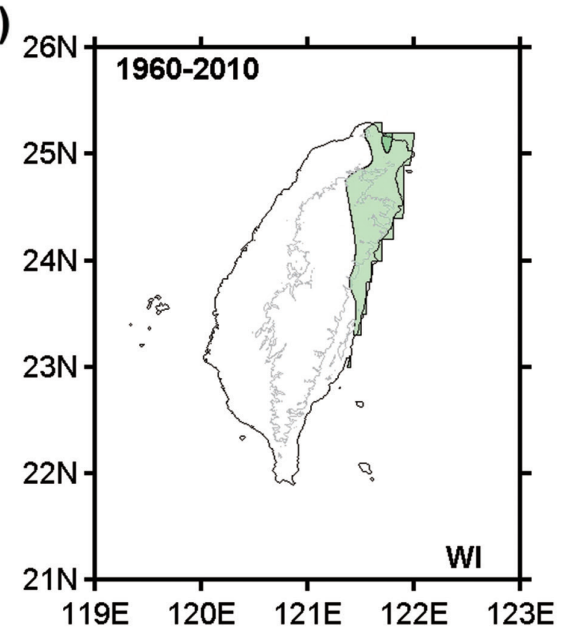

(c)

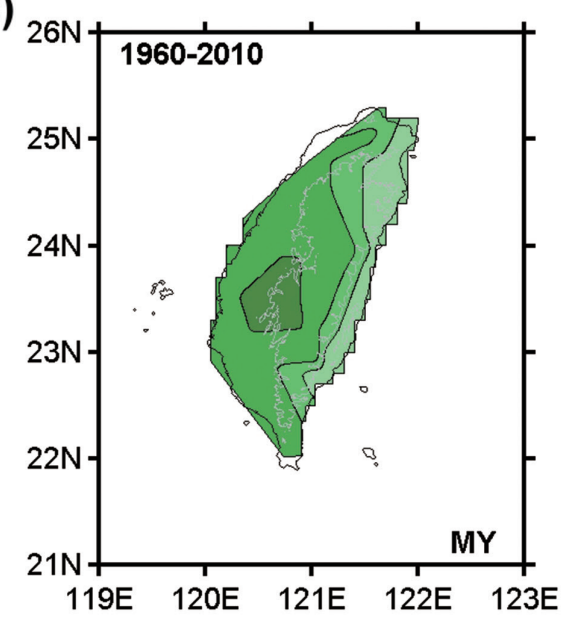

(e)

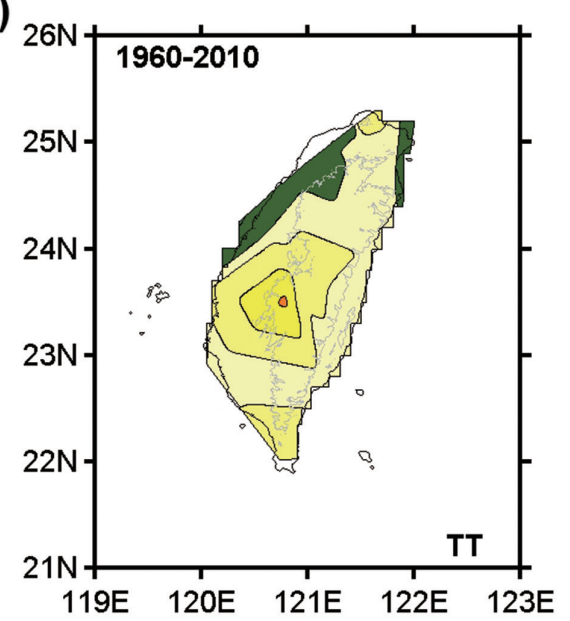

(b)

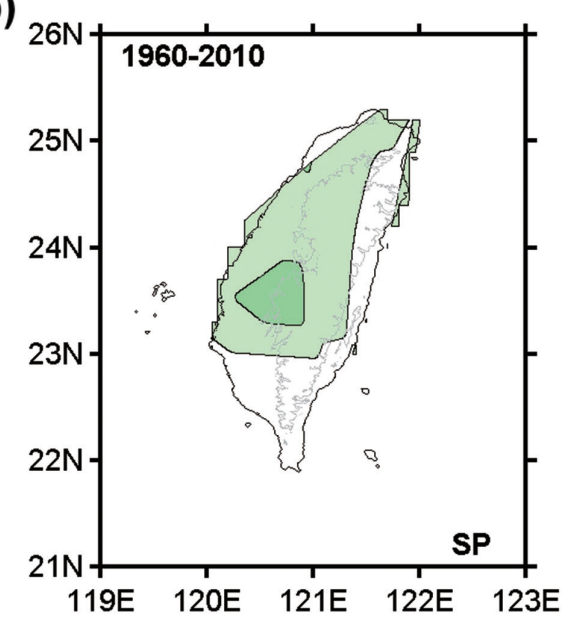

(d)

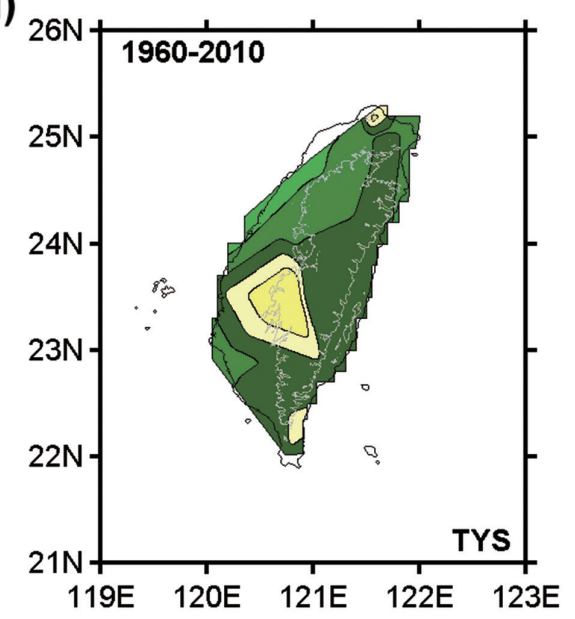

Fig. 6. Spatial distributions of Taiwan 95th percentile extreme rain from 1960-2010 for (a) Winter, (b) Spring, (c) Mei-Yu, (d) Typhoon season, and (e) total amount. The terrain contour is $800 \mathrm{~m}$ altitude. 
(a)

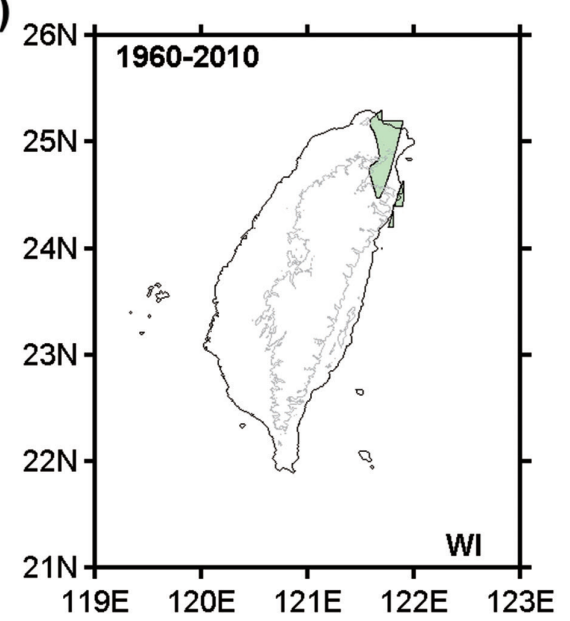

(c)

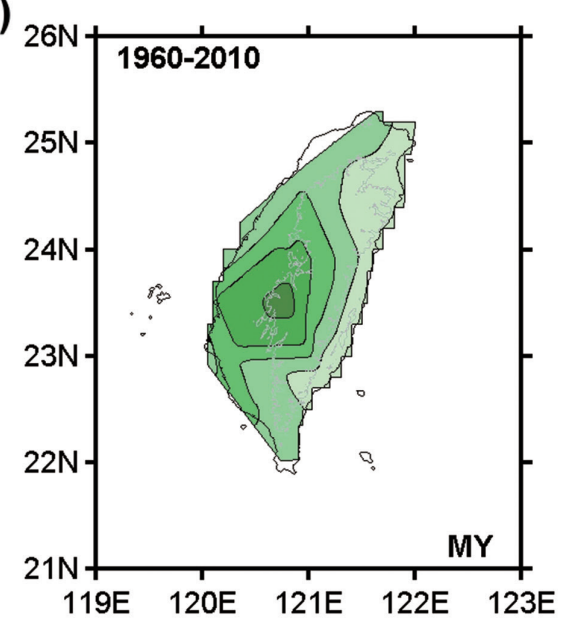

(e)

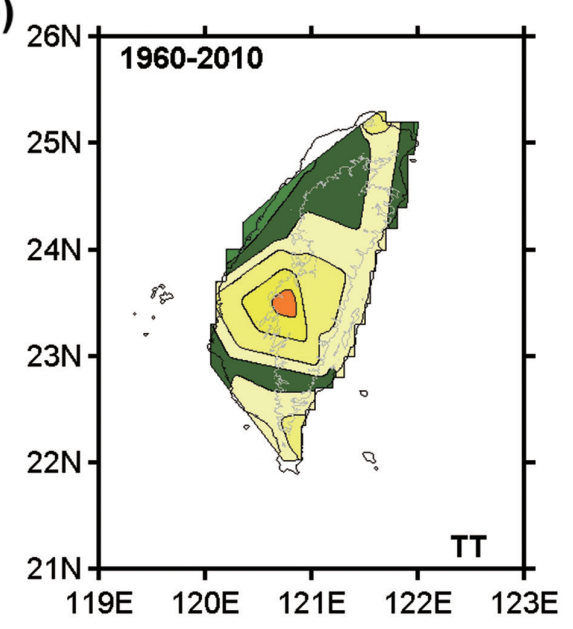

(b)

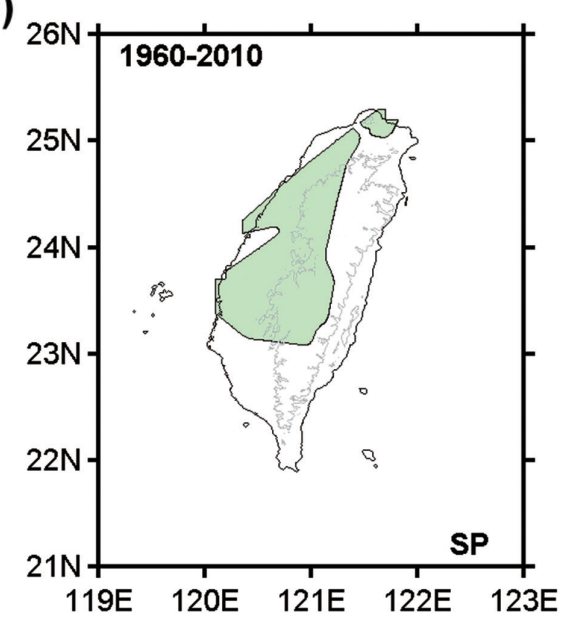

(d)

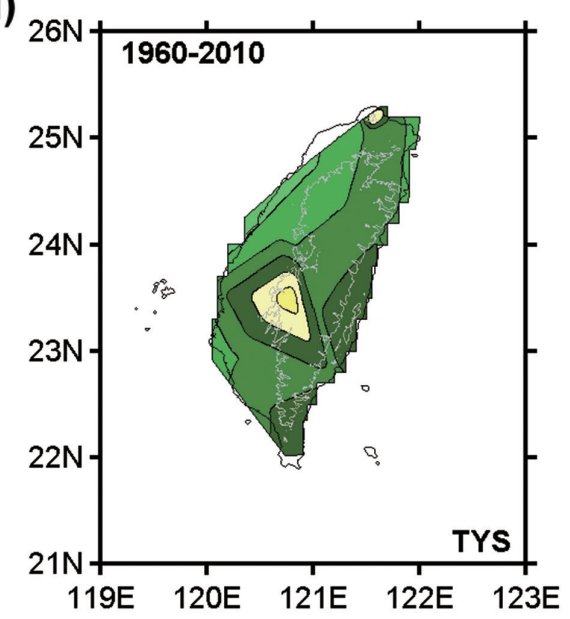

Fig. 7. Same as Fig. 6 except for frequency. 
(a)

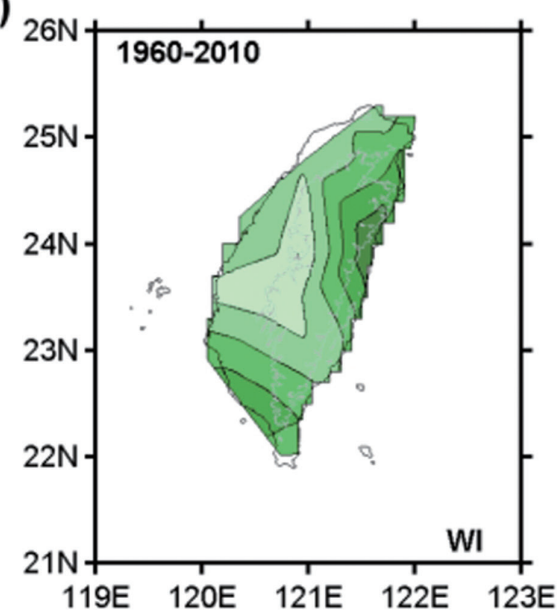

(c)

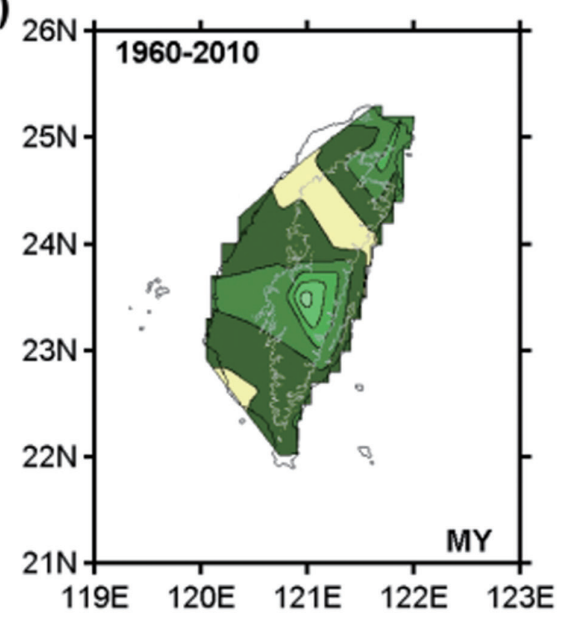

(e)

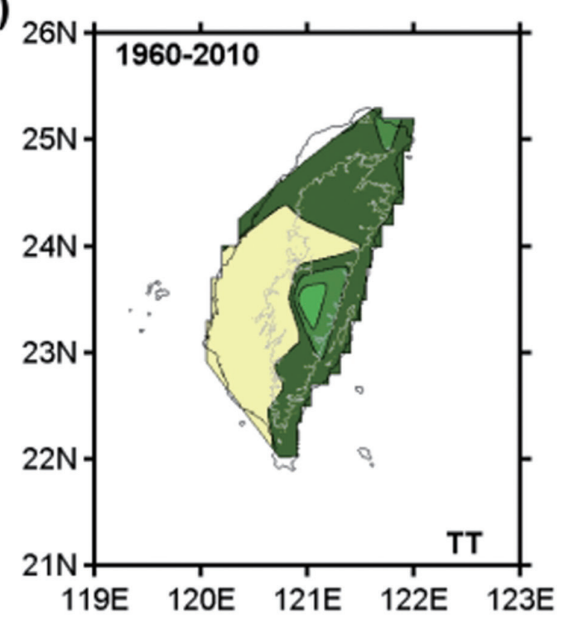

(b)

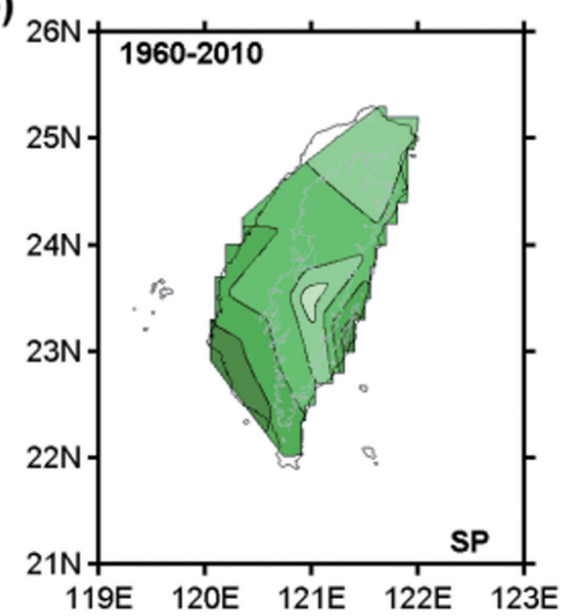

(d)

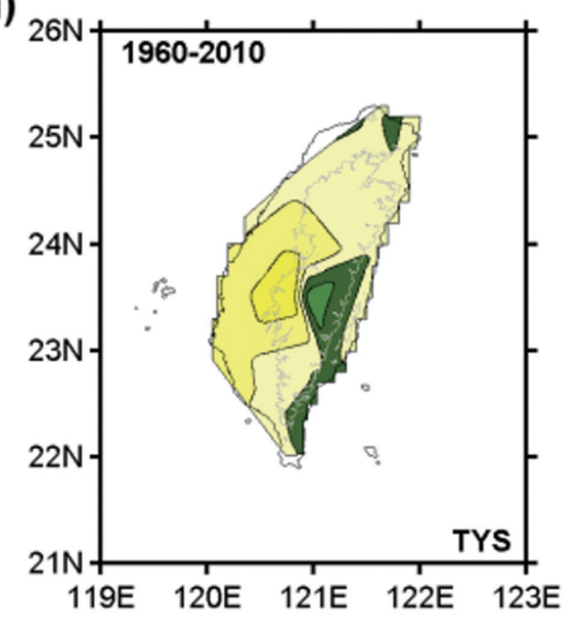

Fig. 8. Same as Fig. 6 except for averaged rain intensity. 
(a)

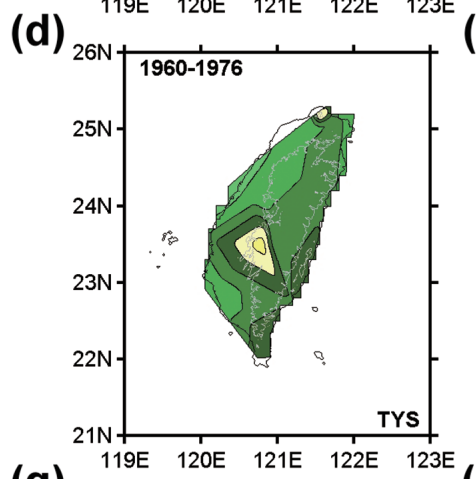

(g)

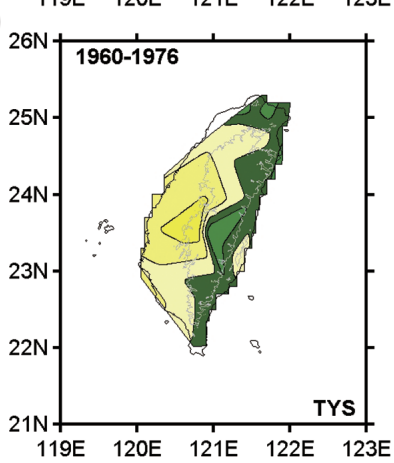

(b)

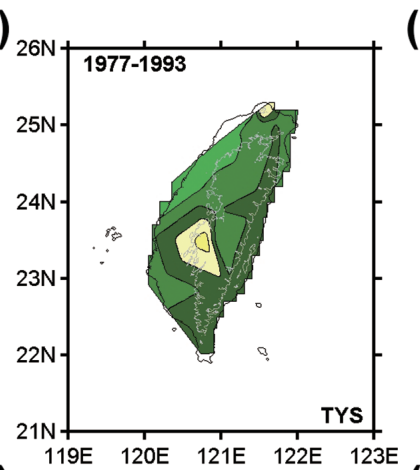

(e)

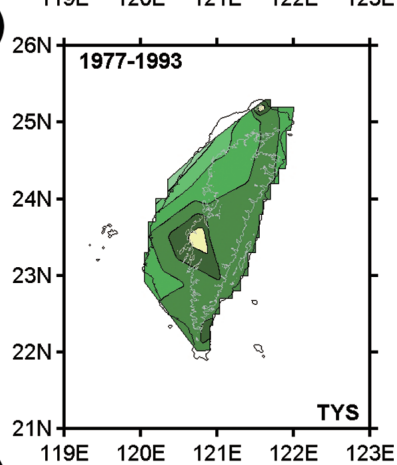

(h)

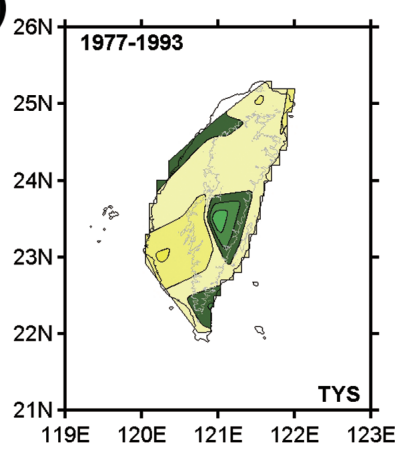

(c)

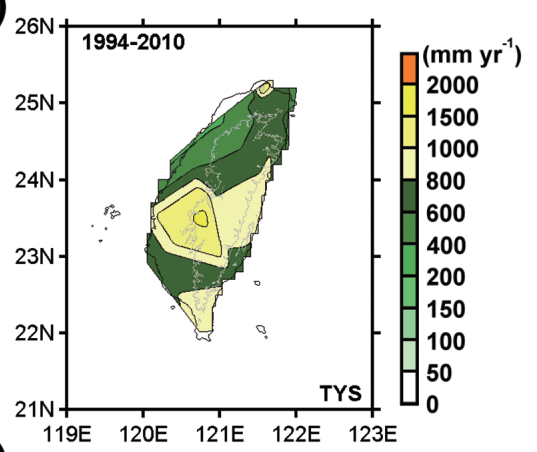

(f)

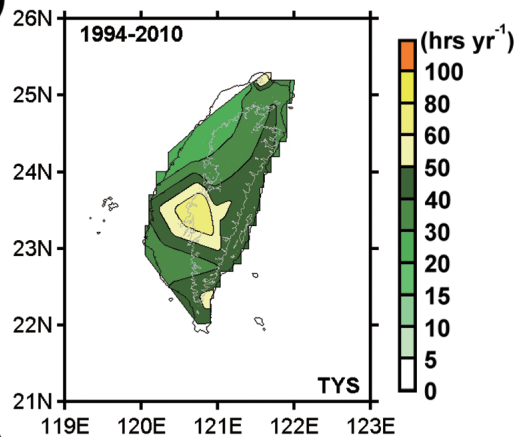

(i)

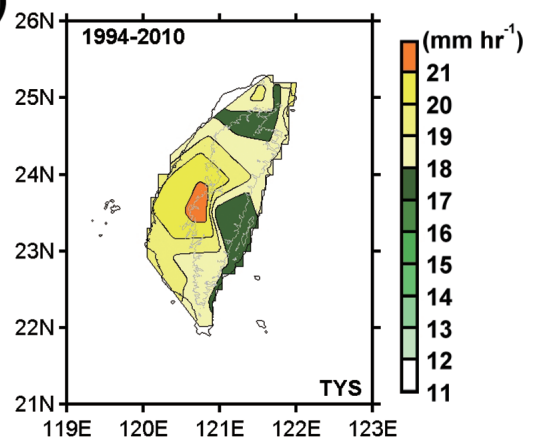

Fig. 9. Spatial distributions of typhoon season accumulated 95th percentile extreme rainfall ((a), (b) and (c)), frequency ((d), (e), and (f)) and averaged rain intensity ((g), (h) and (i)) for the 1960-1976, 1977-1993, and 19942010 decadal periods. The terrain contour is $800 \mathrm{~m}$ altitude.

(Fig. 1) that made landfall on the Taiwan east-coast from 1960 to 2010 (67 typhoons). Table 2 is the average values of typhoon duration, distance, translation speed, ER amount, and total rainfall value during the landfall period in each track type. Table 2 indicates that average duration time for landfall typhoons with type $2(\mathrm{~N})$ and 3(C) tracks are about 3 hours longer than that of type 4(S) tracks, and are likely to produce three to four times as much ER. This may be due to the fact that type 2(N) and 3(C) tracks are more likely to produce windward side rainfall over the slopes of CMR than that of type
4(S) (Chang et al. 1993). The landfall duration time is about the same for type $2(\mathrm{~N})$ and $3(\mathrm{C})$ tracks; but the distance of type 3(C) tracks is about $50 \mathrm{~km}$ longer that for type $2(\mathrm{~N})$ and $4(\mathrm{~S})$ tracks. The typhoon translation speed across Taiwan is slowest for type 2(N) tracks. It is possible that the phase-locked precipitation on the windward side of mountain slope may produce potential vorticity tendencies which slow down the general northwest moving storm. Table 2 suggests the importance of the CMR mountain modulation on the ER and the total rainfall amount. 
Table 2. The average values of Typhoon duration, distance, translation speed, extreme rainfall amount (ERA), and total rainfall during the landfall period. Three columns are for the types of CWB tracks: type $2\left(\right.$ North, $\left.24^{\circ} \mathrm{N}-25^{\circ} \mathrm{N}\right)$, type $3\left(\right.$ Center, $\left.23^{\circ} \mathrm{N}-24^{\circ} \mathrm{N}\right)$ and type 4 (South, $\left.22^{\circ} \mathrm{N}-23^{\circ} \mathrm{N}\right)$.

\begin{tabular}{cccc}
\hline 1960-2010 & Type 2(N) & Type 3(C) & Type 4(S) \\
\hline Case Number & 34 & 20 & 13 \\
\hline Duration $\left(\mathrm{hr} \mathrm{TY}^{-1}\right)$ & 8.4 & 8.9 & 5.5 \\
Distance $\left(\mathrm{km} \mathrm{TY}^{-1}\right)$ & 125.3 & 175.3 & 129.5 \\
Translation speed $\left(\mathrm{m} \mathrm{s}^{-1}\right)$ & 7.3 & 8.6 & 8.7 \\
95th percentile ERA $\left(\mathrm{mm} \mathrm{TY}^{-1}\right)$ & 957.7 & 809.5 & 264.3 \\
99.5th percentile ERA $\left(\mathrm{mm} \mathrm{TY}^{-1}\right)$ & 470.1 & 347.1 & 115.0 \\
Total rainfall amount $\left(\mathrm{mm} \mathrm{TY}^{-1}\right)$ & 1180.3 & 1084.5 & 438.5 \\
\hline
\end{tabular}

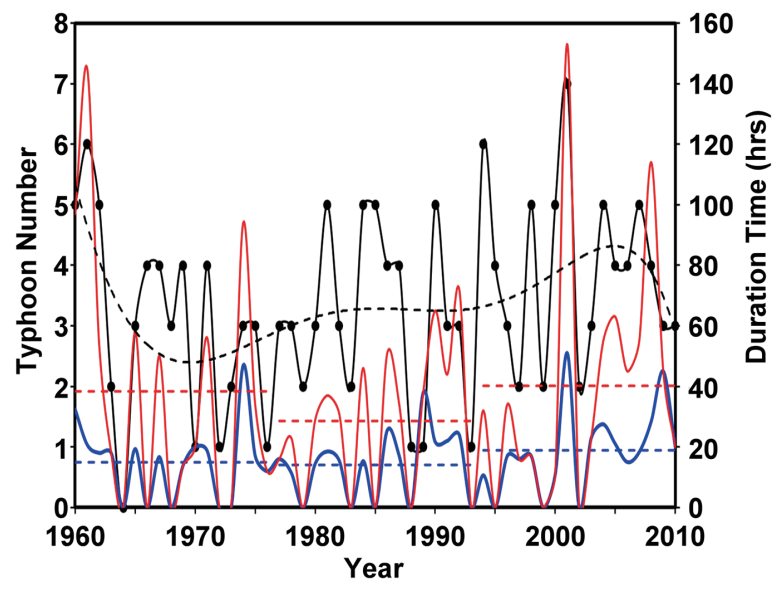

Fig. 10. The annual variation of the typhoon numbers (black, dashed is the 6th order regression) near Taiwan, the annual total landfall duration time (red) and the duration time per typhoon in each year (blue) from 1960-2010. The averaged values of the total duration and duration per typhoon in the three decadal periods are indicated by dashed lines.

Figure 11a shows the ER for each typhoon as a function of translation speed and typhoon intensity, with the typhoon intensity from the CWB typhoon database. The typhoon categories are according to the Saffir-Simpson Hurricane Scale (Simpson 1974). Saffir-Simpson Hurricane Scale is based on wind speed that showed expected damage to structures. The original idea was to describe the damage to low-cost housing along the coastal area but it was also used to classify the typhoon strength. Figure 11a suggests that the amount of typhoon ER is related to the typhoon translation speed but not TC intensity. Moreover, Fig. (a)
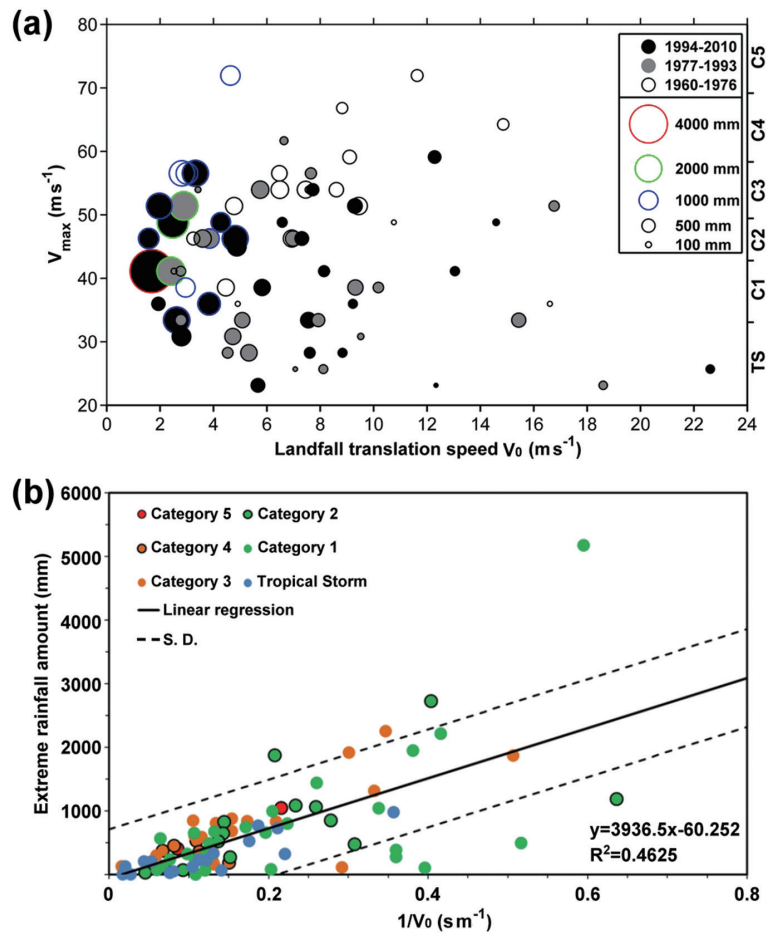

Fig. 11. (a) Total 95th percentile extreme rainfall $(\mathrm{mm})$ as a function of typhoon intensity (maximum wind speed) and translation speed from 1960 to 2010 . Rainfall is proportional to the circle size; the three decadal periods are shaded differently. (b) The 95th percentile extreme rainfall $(\mathrm{mm})$ versus the reciprocal of typhoon translation speed $\left(\mathrm{s} \mathrm{m}^{1}\right)$, with colors denoting the typhoon intensity from tropical storm to Category 5 . The dashed line indicates the range of one standard deviation. 
(a)

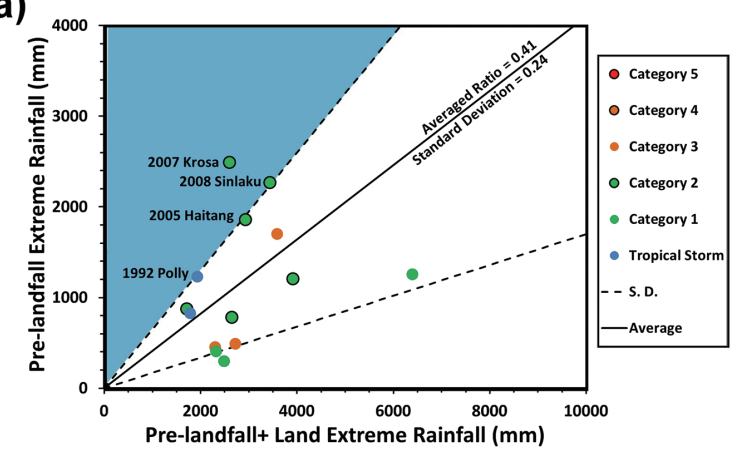

(b)

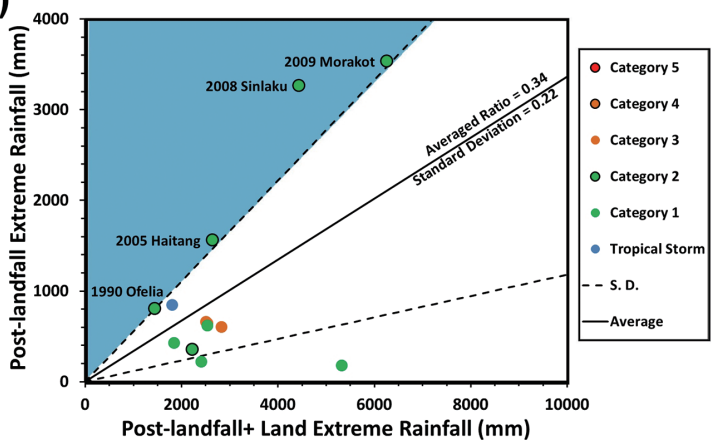

Fig. 12. (a) Pre-landfall 95th percentile extreme rainfall $(\mathrm{mm})$ versus the pre-landfall and landfall accumulated 95th percentile extreme rainfall (mm) from 1977-2010. (b) is similar to (a) except for the post-landfall 95th percentile extreme rainfall $(\mathrm{mm})$ cases. The solid lines are the averaged ratios; and the dashed lines are the range of one standard deviation.

11a indicates that there was more typhoon ER in the 1994-2010 period, and most of the typhoons had slower translation speeds. Figure $11 \mathrm{~b}$ is the typhoon ER amount as a function of translation speed, along with the lines of regression and one standard deviation. The reciprocal of translation speed is plotted for graphical clarity. It clearly indicates that ER is closely related to the translation speed. Most of intense (weak) storms are above (below) the regression line in Fig. $11 \mathrm{~b}$. This suggests that intensity may influence ER to some extent, but the influence is still smaller than that of the translation speed. Overall, Fig. 11 suggests that slower translation speed and longer duration time lead to larger ER. These results are in general agreement with Chien and Kuo (2011), which show that Taiwan typhoon total rainfall is closely related to the translation speed rather than intensity. Recently, Marks (2011, personal communication) also noted that Atlantic

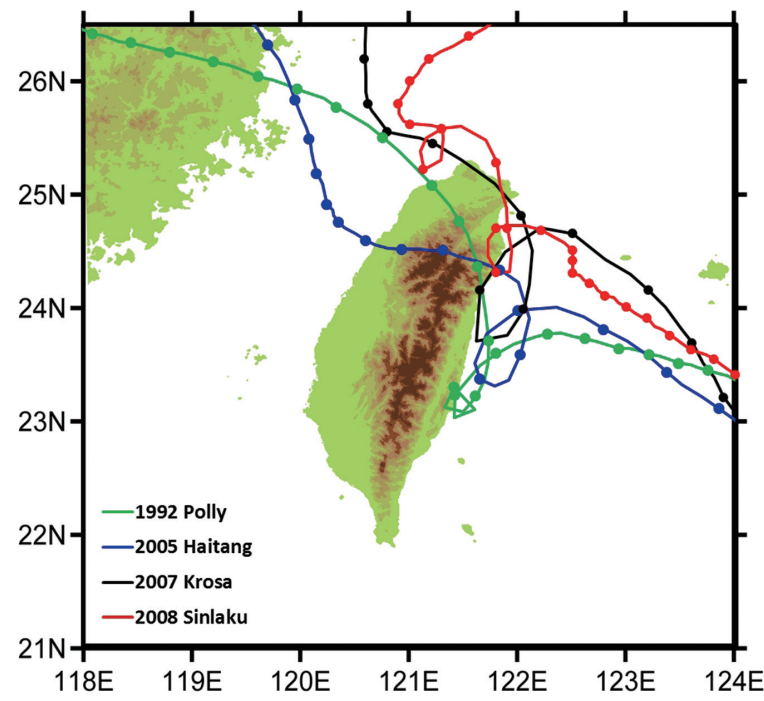

Fig. 13. Tracks of four pre-landfall dominated typhoons from CWB hourly typhoon track data. The dots are the positions every three hours.

hurricane rainfall is closely related to the duration time and translation speed.

Most of the ER occurs in the typhoon landfall period. However there are a few cases of typhoons which produce more ER over Taiwan before or after the landfall period. We identify these cases using the data from 1977 to 2010, as the typhoon positions over the ocean are better defined in this period. Figure 12a shows a comparison of ER in the pre-landfall and landfall period for those typhoon cases with more than $2,000 \mathrm{~mm}$ total rainfall. We identify the pre-landfall dominated typhoon as the typhoons that have more ER during the pre-landfall period (greater or equal to one standard deviation, in the blue color region). Similarly, the post-landfall dominated ER cases are identified in Fig. 12b. There are four pre-landfall ER dominated typhoon cases: Polly (1992), Haitang (2005), Krosa (2007), and Sinlaku (2008). Figure 13 depicts the tracks of these four typhoons. All four tracks show a similar looping pattern and all are north of 23 degrees latitude. This type of track looping or southward deflection before landfall may lengthen the typhoon duration time in the pre-landfall period. Track looping or deflection may be due to the interaction of the typhoon circulation with the topography before the landfall. Yeh and Elsberry (1993a) showed that the terrain may enhance the southward flow on the eastern side of land by the channel effect, a result also found by Jian and $\mathrm{Wu}$ 
(a)

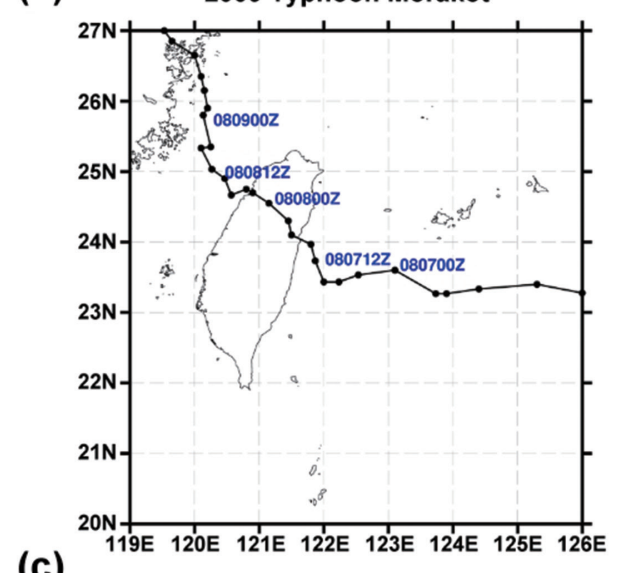

(c) $2009080712 Z 925 \mathrm{mb}$ water vapor flux

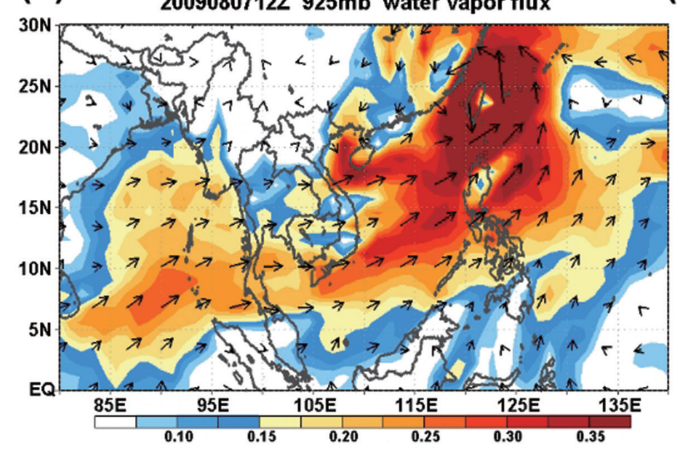

(b)

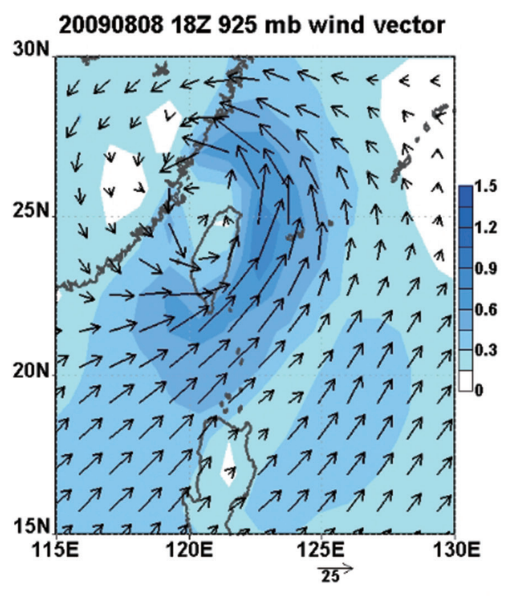

(d)

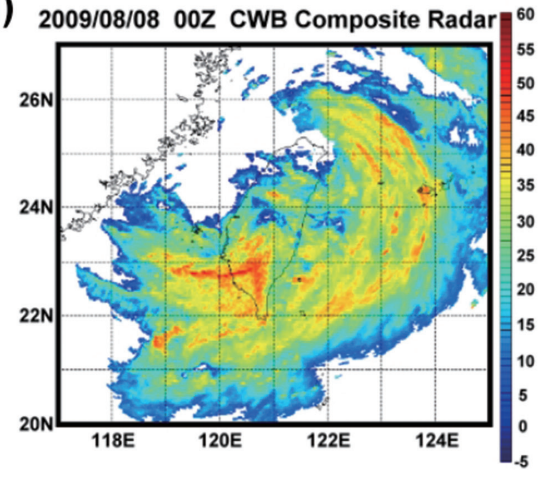

Fig. 14. The special features of Typhoon Morakot (2009): (a) track of typhoon Morakot with three hour positioning data, (b) $925 \mathrm{mb}$ wind vectors and water vapor flux $\left(\mathrm{m} \mathrm{s}^{-1} \mathrm{~kg} \mathrm{~kg}^{-1}\right.$ ) at 18Z, Aug. 8, 2009, (c) water vapor flux (m $\mathrm{s}^{-1} \mathrm{~kg} \mathrm{~kg}^{-1}$ ) at $925 \mathrm{mb}$ at 12Z, Aug. 07, 2009 (water vapor flux is shaded and arrows are the wind vectors), (d) CWB composite radar reflectivity at 00Z, Aug. 8, 2009.

(2008). On the other hand, Kuo et al. (2001) suggests that the effect of topographic vortex stretching by the typhoon circulation across the CMR may cause the typhoon vortex to move southward before landfall. Yeh et al. (2011) used numerical model experiments to study the looping track of Typhoon Haitang (2005), and showed that the interaction of the typhoon with a typhoon induced secondary vortex may also contribute to this looping behavior.

An example of a post-landfall dominate case is Typhoon Morakot (2009), which possessed the highest recorded rainfall in Taiwan in the past 51 years. The slow translation speed of Typhoon Morakot both during landfall and in the post-landfall periods, the southwest monsoon supply of moisture, the multiple scale interaction with the intra-seasonal oscillation, and mesoscale convection in the convergent zone of typhoon-monsoon flows are the primary factors for the ER events (Ge et al. 2008; Hong et al. 2010; Chien and Kuo 2011). In this case, a strong low-level convergence line was caused by the intersection of the northwesterly circulation of Morakot and the southwestly monsoon flow. Figure 14 gives the important features of Typhoon Morakot (2009) that produced ER. Note that in Fig. 14c, the southwestly monsoon flow extends throughout the region from the Bay of Bengal to South China Sea.

Finally, we note that the interaction of typhoon circulation with the northeast winter monsoon may also lead to ER. This ER scenario usually occurs in the months of September and October when a typhoon is near the Philippine coast far away from Taiwan. An example of typhoon interaction with the winter monsoon is Typhoon Megi (2010), which made landfall in northeastern Luzon on Oct. 18. After passing Luzon Island, Typhoon Megi rapidly regained strength in the South China Sea and move northwestward and then north-northeastward. The intensity of Typhoon 
(a)

(c)
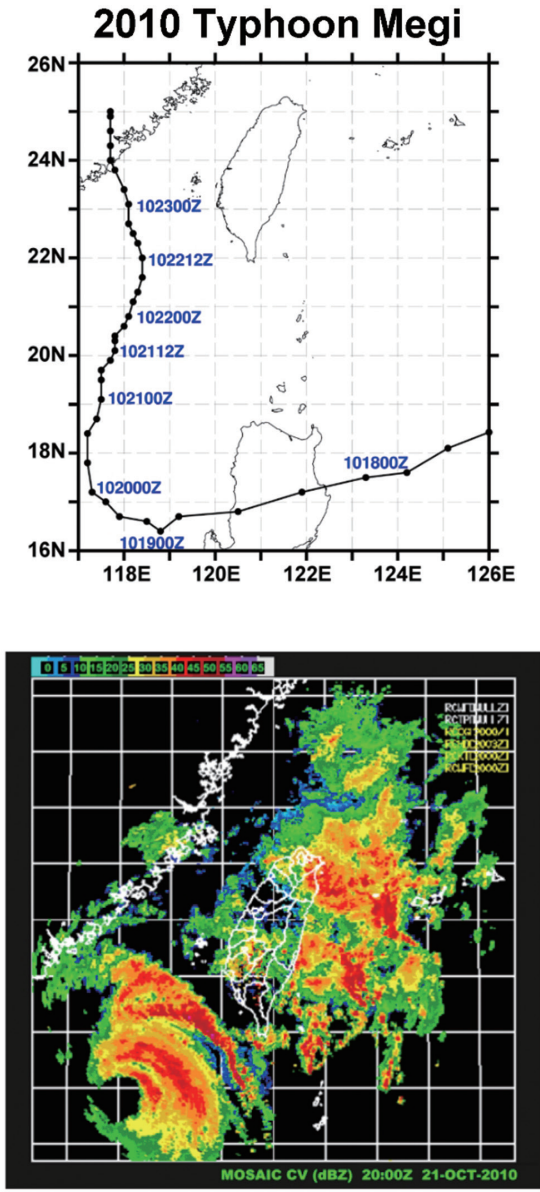

(b)

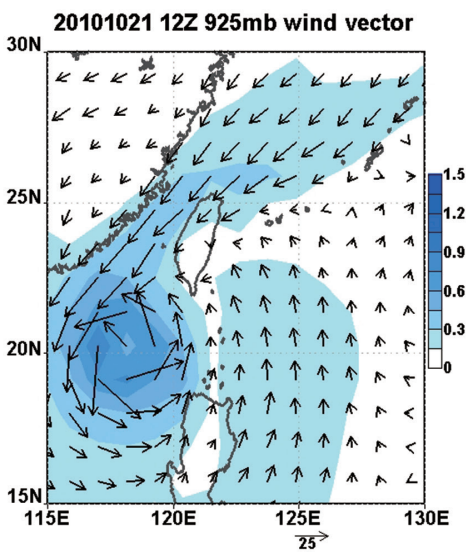

(d)

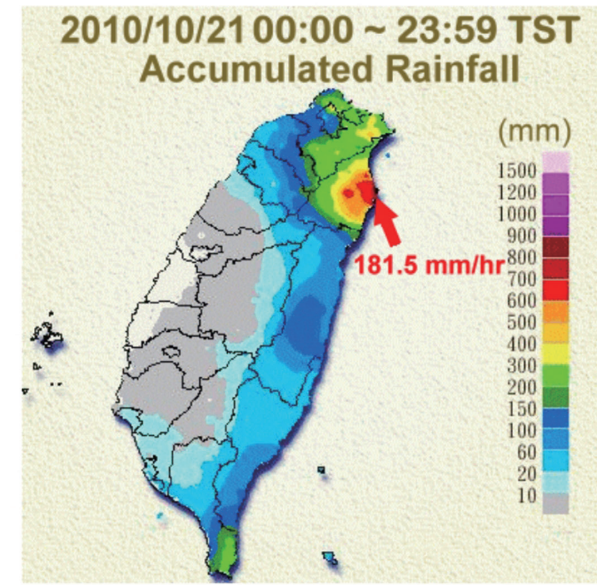

Fig. 15. The special features of Typhoon Megi (2010): (a) track of typhoon Megi (2010) from CWB, (b) $925 \mathrm{mb}$ wind vectors and water vapor flux $\left(\mathrm{m} \mathrm{s}^{-1} \mathrm{~kg} \mathrm{~kg}^{-1}\right)$ at 12Z, Oct. 21, 2010, (c) CWB composite radar reflectivity at 20Z, Oct. 21, 2010, (d) CWB daily accumulated rainfall on Oct. 21. The extreme rain intensity of $181.5 \mathrm{~mm} \mathrm{hr}^{-1}$ at Suao station is indicated.

Megi was decreasing near the south end of Taiwan Straits on Oct. 20 with a slow translation speed of $9 \mathrm{~km}$ $\mathrm{hr}^{-1}$ after Oct. 21. The typhoon track never made landfall in Taiwan (Fig. 15a) but still caused severe rainfall in northeastern Taiwan on Oct. 21. The ER pattern produced is similar to that of Fig. 6a the WI season ER pattern. We noticed the presence of strong MCSs over northeastern Taiwan (Fig. 15c) in the general convergent region of typhoon circulation and the northeast monsoon (Fig. 15b). The torrential rainfall in this case was $1,182 \mathrm{~mm}$ in 24 hours (Suao station), and the peak rain intensity observed was $181.6 \mathrm{~mm} \mathrm{hr}^{-1}$.

\section{Summary}

Using CWB hourly precipitation data from 21 surface stations for a 51-year period (1960-2010), we study extreme rainfall (ER) in Taiwan. The ER is defined as the 95th percentile intensity of total rain events, or equivalently, rain events greater than $9 \mathrm{~mm}$ $\mathrm{hr}^{-1}$ that contribute $40 \%$ of total rain amount in Taiwan. Our major findings are:

(1) Approximately $70 \%$ of ER occurs in the typhoon season (July to October), 20\% in the Mei-Yu (MY) season (May and June), and the other $10 \%$ in the remainder of the year.

(2) The MY ER events, while possessing strong annual variations, do not have significant decadal variation in the 51-year data record.

(3) There is a strong correlation between the yearly value of TYS ER values and the yearly value of 
total ER in Taiwan. The typhoon ER pattern is phased locked with the CMR, with peak values of ER at the Alishan mountain station. Topographic forcing plays a vital role in typhoon ER.

(4) There are significant variations in typhoon ER over the annual and decadal time scales, with greater ER and frequency in the periods of 1960-1976 and 1994-2010, and less in the 1977-1993 period. In particular, the recent 1994-2010 period exhibited larger annual variability and had an increase in ER of $150 \mathrm{~mm} \mathrm{yr}^{-1}$ from the previous decadal period. The averaged typhoon rain intensity, however, is about the same being $19 \mathrm{~mm} \mathrm{hr}^{-1}$ in all the three periods.

(5) The typhoon ER is related to typhoon translation speed rather than typhoon intensity. Slower speed and longer duration time lead to larger ER. Our analyses also indicated that the mean duration time of typhoons making landfall in Taiwan with type 2(N) and 3(C) tracks is about 3 hours longer than that of type $4(\mathrm{~S})$ track typhoons in the last 51 years, and is likely to produce three to four times as much ER.

(6) Westward moving typhoon cases, that produce greater ER when the typhoon centers were over the ocean, are identified. All the pre-landfall dominated typhoons had type 2(N) and 3(C) tracks with a southward deflection or looping tracks during pre-landfall period.

(7) The interactions of summer or winter monsoons with typhoons are also important factors that contribute to ER in Taiwan. Examples of summer monsoon interaction (i.e., Typhoon Morakot 2009) and winter monsoon interaction (i.e., Typhoon Megi 2010) are discussed. The interaction of typhoon circulation and the monsoon flows lead to the formation of mesoscale convective systems in the convergent area. The mesoscale convection is responsible for the ER in Taiwan. The moisture supply by the monsoon flow and the slow typhoon translation speed near Taiwan are key factors in extreme precipitation.

\section{Acknowledgments}

We thank Chih-Pei Chang, Robert G. Fovell and Paul Ciesielski for their helpful comments and suggestions. We thank Hung-Jui Yu, Wan-Ting Chen and Chia-Wei Hsu for their help in processing the data. This research was supported by the Central Weather Bureau through grants MOTC-CWB-100-6M-01 and the National Science Council of Taiwan through grants NSC100-2628-M-002-019, NSC97-2628-M-002-023,
NSC100-2111-M-002-004-MY3, and to National Taiwan University. We thank the Central Weather Bureau for their typhoon database which provided the rainfall data.

\section{References}

Chang, S. W., 1982: The orographic effects induced by an island mountain range on propagating tropical cyclone. Mon. Wea. Rev., 110, 1255-1272.

Chang, C. P., T. C. Yeh, and J. M. Chen, 1993: Effect of terrain on the surface structure of typhoons over Taiwan. Mon. Wea. Rev., 121, 734-752.

Chen, C. S., W. S. Chen, and Z. Deng, 1991: A study of a mountain- generated precipitation system in northern Taiwan during TAMEX IOP8. Mon. Wea. Rev., 119, 2574-2606.

Chien, F. C., and H. C. Kuo, 2011: On the extreme rainfall of Typhoon Morakot (2009), J. Geophys. Res., 116, D05104, doi: 10.1029/2010JD015092.

Fujibe, F., N. Yamazaki, M. Katsuyama, and K. Kobayashi, 2005: The increasing trend of intense precipitation in Japan based on four-hourly data for a hundred years. SOLA, 1, 41-44.

Fujibe, F., N. Yamazaki, and K. Kobayashi, 2006: Long-tern changes of heavy precipitation and dry weather in Japan (1901-2004). J. Meteor. Soc. Japan, 84, 10331046.

Ge, X., T. Li, Y. Wang, and M. Peng (2008), Tropical cyclone energy dispersion in a three-dimensional primitive equation model: upper tropospheric influence. $J$. Atmos. Sci., 65, 2272-2289.

Goswami, B. N., V. Venugopal, D. Sengupta, M. S. Madhusoodanan, and P. K. Xavier, 2006: Increasing trend of extreme rain events over India in a warming environment. Science, 314, 1442-1445.

Hartmann, D. L., J. M. Wallace, V. Limpasuvan, D. W. J. Thompson, and J. R. Holton, 2000: Can ozone depletion and global warming interact to produce rapid climate change? Proc. Natl. Acad. Sci. USA, 97, 14121417.

Haylock, M., and N. Nicholls, 2000: Trends in extreme rainfall indices for an updated high quality data set for Australia, 1910-1998. Int. J. Climatol. 20, 1533-1541.

Haylock, M. R., T. C. Peterson, L. M. Alves, T. Ambrizzi, Y. M. T. Anumciacao, J. Baez, V. R. Barros, M. A. Berlato, M.Bidegain, G. Coronel, V. Corradi, V. J. Garcia, A. M. Grimm, D. Karoly, J. A. Marengo, M. B. Marino, D. F. Moncunill, D. Nechet, J. Quintana, E. Rebello, M. Rusticucci, J. L. Santos, I. Trebejo and L. A. Vincent, 2006: Trends in total and extreme south American rainfall in 1960-2000 and links with sea surface temperature. J. Climate, 19, 1490-1512.

Ho, C. H., J. J. Baik, J. H. Kim, D. Y. Gong, and C. H. Sui, 2004: Interdecadal changes in summertime typhoon tracks. J. Climate, 17, 1767-1776. 
Hong, C. C., M. Y. Lee, H. H. Hsu, and J. L. Kuo (2010), Role of submonthly disturbance and 40-50 day ISO on the extreme rainfall event associated with Typhoon Morakot (2009) in Southern Taiwan. Geophys. Res. Lett., 37, L08805, doi: 10.1029/2010GL042761.

Hsu, H. H., and C. T. Chen, 2002: Observed and projected climate change in Taiwan. Meteorol. Atmos. Phys., 79, 87-104.

Hung, C. W., H. H. Hsu, and M. M. Lu, 2004: Decadal oscillation of spring rain in north Taiwan. Geophys. Res. Lett., 31, L22206, doi: 10.1029/2004GL021344.

Hung, C. W., and P. K. Kao, 2010: Weakening of the winter Monsoon and abrupt increase of winter rainfalls over northern Taiwan and Southern China in the early 1980s. J. Climate, 23, 2457-2467.

Japan Meteorological Agency (JMA), 2010: Climate Change Monitoring Report 2009., 99pp.

Jian, G. J., and C. C. Wu, 2008: A numerical study of the track deflection of Super-typhoon Haitang (2005) prior to its landfall in Taiwan. Mon. Wea. Rev., 136, 598-615.

Karl, T. R., and R. W. Knight, 1998: Secular trend of precipitation amount, frequency, and intensity in the United States. Bull. Amer. Meteor. Soc., 79, 231-242.

Karl, T. R., J. M. Melillo, and T. C. Peterson, 2009: Global Climate Change Impacts in the United States. Cambridge University Press, 189 pp.

Kuo, H. C., R. T. Williams, J. H. Chen, and Y. L. Chen, 2001: Topographic effects on barotropic vortex motion: no mean flow. J. Atmos. Sci. 58, 1310-1327.

Kunkel, K. E., K. Andsager, and D. R. Easterling, 1999: Long-term trends in extreme precipitation events over the conterminous United States and Canada. $J$. Climate, 12, 2515-2527.

Lander, M. A., 1994: An exploratory analysis of the relationship between tropical storm formation in the western North Pacific and ENSO. Mon. Wea. Rev., 122, 636-651.

Lau, K. M., and H. T. Wu, 2007: Detecting trends in tropical rainfall characteristics, 1979-2003. Int. J. Climatol., 27, 979-988.

Liu, K. S., and J. C. L. Chan, 2008: Interdecadal variability of western North Pacific tropical cyclone tracks. $J$. Climate, 21, 4464-4476.

Liu, S. C., C. Fu, C. J. Shiu, J. P. Chen, and F. Wu, 2009: Temperature dependence of global precipitation extremes. Geophys. Res. Lett., 36, L17702, doi: 10.1029/2009GL040218.

Lu, M. M., and R. J. May, 2003: A study on the long-term variations of Taiwan and Global Precipitation. Atmos. Sci., 31, 199-220.

Lu, M. M., C. J. Chen, and Y. C. Lin, 2007: Long-term Variations of the Occurrence Frequency of Extreme Rainfall
Events during the Period of 1951-2005. Atmos. Sci., 35, 87-103.

Manton, M. J., P. M. Della-Marta, M. R. Haylock, K. J. Hennessy, N. Nicholls, L. E. Chambers, D. A. Collins, G. Daw, A. Finet, D. Gunawan, K. Inape, H. Isobe, T. S. Kestin, P. Lefale, C. H. Leyu, T. Lwin, L. Maitrepierre, N. Ouprasitwong, C. M. Page, J. Pahalad, N. Plummer, M. J. Salinger, R. Suppiah, V. L. Tran, B. Trewin, I. Tibig, and D. Yee, 2001: Trends in extreme daily rainfall and temperature in southeast Asia and the south Pacific: 1961-1998. Int. J. Climatol., 21, 269-284.

Peralta-Hernández A. R., R. C. Balling. Jr., and L. R. BarbaMartínez, 2009: Comparative analysis of indices of extreme rainfall events: Variations and trends from southern México. Atmósfera, 15, 147-164.

Piao, S., P. Ciais, Y. Hung, Z. Shen, S. Peng, J Li, L. Zhou, H. Liu, Y. Ma, Y. Ding, p. Friedlingstein, C. Liu, K. Tan, Y. Yu, T. Zhang, and J. Fang, 2010: The impacts of climate change on water resources and agriculture in China. Nature, 467, 43-51.

Salinger, M. J., and G. M. Griffiths, 2001: Trends in New Zealand daily temperature and rainfall extremes. Int. J. Climate, 21, 1437-1452.

Shieh, S. L., S. T. Wang, M. D. Cheng, and T. C. Yeh, 1998: Tropical cyclone tracks over Taiwan and its vicinity for the one hundred years 1897 to 1996 (in Chinese). Research Rep. CWB86-1M- 01, Central Weather Bureau, Taipei, Taiwan, 497 pp.

Simpson, R. H., 1974: The hurricane disaster potential scale. Weatherwise, 27, 169-186

Suppiah, R., and K. J. Hennessy, 1998: Trends in total rainfall, heavy rain events and number of dry days in Australia, 1910-1990. Int. J. Climatol. 10, 1141-1164.

Tolika, K., Chr. Anagnostopoulou, P. Maheras, and H. Kutiel, 2007: Extreme precipitation related to circulation types for four case studies over the Eastern Mediterranean. Adv. Geosci., 12, 87-93.

Wang, S. T., 1980: Prediction of the behavior and intensity of typhoons in Taiwan and its vicinity (in Chinese). Research Rep., 108, Chinese National Science Council, Taipei, Taiwan, 100pp.

Yeh, T. C., and R. L. Elsberry, 1993a: Interaction of typhoons with the orography. Part I: Upstream track deflections. Mon. Wea. Rev., 121, 3193-3212.

Yeh, T.-C., L.-F. Hsiao, D.-S. Chen, and K.-N. Huang, 2011: A study on terrain induced tropical cyclone looping in East Taiwan: case study of Typhoon Haitang in 2005. Nat. Hazards, doi: 10.1007/s11069-011-9876-7.

Zhai, P., X. Zhang, H. Wan, and X. Pan, 2005: Trends in total precipitation and frequency of daily precipitation extremes over China. J. Climate, 18, 1096-1108. 